\title{
CONSTRUCTED WETLANDS DENGAN TUMBUHAN ECENG GONDOK (Eichhornia crassipes) SEBAGAI ALTERNATIF PENGOLAHAN AIR LIMBAH INDUSTRI TAPIOKA
}

\author{
Eko Siswoyo ${ }^{1}$, Faisal $^{1}$, Nur Kumalasari ${ }^{1}$, Kasam ${ }^{1}$ \\ 1) )Program Studi Teknik Lingkungan, Universitas Islam Indonesia \\ E-mail : eko_siswoyo@uii.ac.id
}

\begin{abstract}
Abstrak
Beberapa permasalahan pengolahan air limbah yang sering muncul yaitu mahalnya biaya dan rumitnya operasional instalasi pengolahan air limbah. Hal ini berdampak pada munculnya berbagai permasalahan lingkungan yang diakibatkan oleh pembuangan air limbah ke badan air pengolahan tanpa melalui proses yang baik, misalnya air limbah dari industry tapioka. Constructed wetlands merupakan salah satu metode pengolahan air limbah yang mudah, murah dan memiliki kemampuan yang baik. Penelitian ini bertujuan untuk mengkaji kemampuan conctructed wetlands untuk mengolah air limbah industri tapioka. Jenis reaktor constructed wetlands yang digunakan dalam penelitian ini yaitu Free Water Surface (FWS) secara batch dengan tumbuhan Eceng Gondok (Eichhornia crassipes). Parameter pencemar yang diteliti yaitu BOD, COD, TSS dan Sianida yang ada dalam air limbah industri tapioka dengan beberapa konsentrasi mulai dari 20, 40, 60, 80 dan 100\%. Sedangkan waktu pengamatan dalam penelitian ini yaitu selama 10 hari dimana dilakukan pengambilan sampel uji pada hari ke-0, 2, 4, 6, 8 dan 10. Hasil penelitian ini menunjukkan bahwa constructed wetlands mampu menurunkan kadar BOD, COD, TSS dan Sianida masing-masing mencapai 97,9\%, 84,4\%, 45,6\% dan 99,9\%. Hasil tersebut menunjukkan bahwa constructed wetlands dengan tumbuhan Eceng Gondok memiliki kemampuan yang sangat baik dalam menurunkan pencemar pada air limbah industri tapioka, sehingga dapat dijadikan salah satu alternatif dalam mengatasi permasalahan pencemaran lingkungan akibat air limbah di Indonesia.
\end{abstract}

Kata kunci: Constructed wetlands, eceng gondok, free water surface, air limbah tapioka.

\begin{abstract}
The most common problems of wastewater treatment plant are the high cost and complexity in operation and maintenance. These conditions often cause various environmental problems because of the disposal of wastewater to the water bodies without any proper treatment, for example, wastewater from the tapioca industry. Constructed wetland is one method of treating wastewater which is easy, inexpensive and has excellent capabilities. This study examines the ability of the constructed wetlands to treat tapioca industrial wastewater. The type of constructed wetlands reactor used in this study is Free Water Surface (FWS) in a batch system with water hyacinth plant (Eichhornia crassipes). The current study examined the removal of BOD, COD, TSS and Cyanide in tapioca industrial wastewater with several initial concentrations ranging from 20,40,60, 80 and $100 \%$ for ten days observation $(0,2,4,6,8$ and 10 days of the treatment by the reactor). The results of this study showed that constructed wetlands were able to reduce levels of BOD, COD, TSS and cyanide up to 97.9\%, 84.4\%, 45.6\% and 99.9\%, respectively. These results indicate that the constructed wetlands built with water hyacinth plants have excellent ability to reduce pollutants in tapioca industrial wastewater so that it could overcome the problem of environmental pollution due to wastewater disposal in Indonesia.
\end{abstract}

Keywords: Constructed wetlands, free water surface, tapioca wastewater, water hyacinth.

Dikirim/submitted: 18 Desember 2019

Diterima/accepted: 26 Desember 2019 


\section{PENDAHULUAN}

Berbagai permasalahan pencemaran lingkungan di Indonesia dan beberapa negara berkembang seringkali diakibatkan oleh keterbatasan biaya dan teknologi tepat guna dalam mengolah air limbah. Banyak penghasil limbah baik aktifitas domestik maupun industri yang membuang limbahnya secara langsung ke badan air penerima tanpa melalui pengolahan yang baik terlebih dahulu, sehingga berdampak pada meningkatnya kadar bahan-bahan pencemar yang ada di badan air. Hal ini dapat mengakibatkan dampak negatif bagi lingkungan dan khususnya kesehatan manusia. Salah satu kegiatan industri yang menghasilkan air limbah dalam jumlah yang besar dan memiliki kadar kontaminan yang berbahaya adalah industri tapioka, dimana beberapa industri tersebut juga banyak menimbulkan permaslahan lingkungan akibat terbatasnya sistem pengolahan air limbah. Limbah industri tapioka mengandung bahan organik dan sianida yang tinggi (Mulyani dan Prasadja, 2014) dan (Zhang et al., 2016).

Beberapa metode pengolahan air limbah telah digunakan untuk mengolah air limbah industri tapioka. Irmanto dan Suyata (2010) menggunakan adsorben dari ampas kopi untuk menurunkan kadar Biochemical Oxygen Demand (BOD), Chemical Oxygen Demand (COD) dan Total Suspended Solid (TSS) pada air limbah industri tapioka, adsorpsi-fotodegradasi dengan material dari zeolite (Fatimah dan Wijaya, 2005), proses pengolahan lumpur aktif (Santoso, 2010), fitoremediasi dengan tumbuhan kangkung air (Nurkemalasari et al., 2013 ), klorinasi (Mulyani dan Prasadja, 2014), Rotating Biologycal Contactor (Susilo et al., 2015), serta beberapa metode lainnya. Selain itu limbah cair industri tapioka juga digunakan sebagai bahan pembuatan pupuk cair dengan menggunakan tambahan starter (Cesaria et al., 2014), produksi gas methan (Thepubon et al., 2020), dan bahan pembuatan biosemikonduktor (Wardhana et al., 2019). Dibandingkan dengan beberapa pengolahan tersebut, constructed wetlands yang merupakan sistem pengolahan air limbah secara alamiah memiliki keuntungan antara lain, prosesnya sangat mudah dan memiliki kemampuan dalam menurunkan kontaminan cukup tinggi (Siswoyo et al., 2011) dan (Polprasert, 2004).

Beberapa penelitian terkait pengolahan air limbah industri tapioka telah dilakukan dengan menggunakan jenis tumbuhan seperti kangkung air dan eceng gondok tetapi dan kontaminan tertentu. Sebagai kelanjutan dari penelitian-penelitian sebelumnya, maka pada penelitian ini dilakukan pengujian kemampuan tumbuhan eceng gondok dalam menurunkan BOD, COD, TSS dan sianida dalam air limbah industri tapioka dengan menggunakan reaktor constructed wetlands tipe free water surface (FWS). Selain itu juga dilakukan pengamatan bagaimana 
limbah industri tapioka memberikan pengaruh pada pertumbuhan tumbuhan eceng gondok. Tumbuhan eceng gondok dipilih karena sangat mudah diperoleh dan dapat tumbuh dengan baik pada lingkungan ekstrim. Sedangkan tipe FWS memiliki keunggulan tidak mudah tersumbat oleh kandungan TSS yang tinggi dalam air limbah industri tapioka. Hasil dari penelitian ini diharapkan mampu memberikan informasi terkait sistem pengolahan air limbah industri tapioka yang murah dan memiliki efisiensi tinggi.

\section{METODE PENELITIAN}

\subsection{Pembuatan reaktor constructed wetlands tipe FWS}

Reaktor constructed wetland yang digunakan yaitu tipe FWS dengan ukuran panjang, lebar dan tinggi 1,0 m, 0,5 m dan 0,5 m sebanyak enam buah disesuaikan dengan variasi konsentrasi air limbah industri tapioka yang diuji. Reaktor terbuat dari papan yang dilapisi plastik tebal untuk mencegah kebocoran dan diletakkan dalam sebuah rumah kaca agar penguapan yang terjadi dapat diminimalkan.

\subsection{Proses pelaksanaan penelitian}

Penelitian ini dilakukan dengan proses pengaliran batch, menggunakan berbagai variasi konsentrasi limbah cair industri tapioka 20\%, 40\%, 60\%, 80\% dan 100\% (persen volume) masing-masing sebanyak 75 liter yang disesuaikan dengan kapasitas reaktor. Untuk mengetahui pengaruh keberadaan tumbuhan eceng gondok, maka digunakan air limbah tapioka 100\% tanpa diberi eceng gondok (reaktor kontrol).

Tabel 1. Variasi Konsentrasi Limbah Cair

\begin{tabular}{ccccc}
\hline Reaktor & $\begin{array}{c}\text { Konsentrasi limbah } \\
(\%)\end{array}$ & $\begin{array}{c}\text { Volume } \\
\text { limbah } \\
(\text { Liter })\end{array}$ & $\begin{array}{c}\text { Volume } \\
\text { pengencer } \\
(\text { Liter })\end{array}$ & $\begin{array}{c}\text { Jumlah } \\
\text { tumbuhan } \\
\text { (buah) }\end{array}$ \\
\hline 1 & 100 & 75 & 0 & 30 \\
\hline 2 & 80 & 60 & 15 & 30 \\
\hline 3 & 60 & 45 & 30 & 30 \\
\hline 4 & 40 & 30 & 45 & 30 \\
\hline 5 & 20 & 15 & 60 & 30 \\
\hline 6 & 100 & 75 & 0 & Tanpa tumbuhan \\
\hline
\end{tabular}

Banyaknya jumlah tumbuhan eceng gondok yang digunakan didasarkan pada pertimbangan agar permukaan reaktor tidak tertutup tumbuhan secara penuh. Tumbuhan eceng gondok yang digunakan diambil dari daerah Sleman, dimana dipilih eceng gondok yang memiliki ukuran yang sama sehingga diperkirakan umurnya sama. Pengujian konsentrasi BOD, COD, TSS dan 
Sianida dilakukan di Laboratorium Kualitas Air Universitas Islam Indonesia (UII) dengan mengikuti standar pengujian yang ada.

\section{HASIL DAN PEMBAHASAN}

\subsection{Tingkat penurunan BOD}

Kemampuan constructed wetlands dengan tumbuhan eceng gondok dalam menurunkan kadar BOD pada air limbah industri tapioka sebagaimana terlihat pada gambar 1. Terlihat bahwa terjadi penurunan konsentrasi BOD pada semua variasi air limbah mulai dari hari pertama hingga hari ke-10, dimana variasi konsentrasi 20\% air limbah industri tapioka memberikan hasil paling baik. Hal ini karena kadar BOD pada variasi tersebut paling rendah, sehingga lebih mudah diturunkan. Semakin tinggi konsentrasi air limbah akan memberikan beban pengolahan lebih bagi tumbuhan eceng gondok (Siswoyo et al., 2011). Penurunan BOD tertinggi mencapai 97,9\%, dimana keberadaan tumbuhan eceng gondok sangat penting. Hal ini terlihat dari reaktor kontrol yang hanya mengalami penurunan BOD sangat rendah.

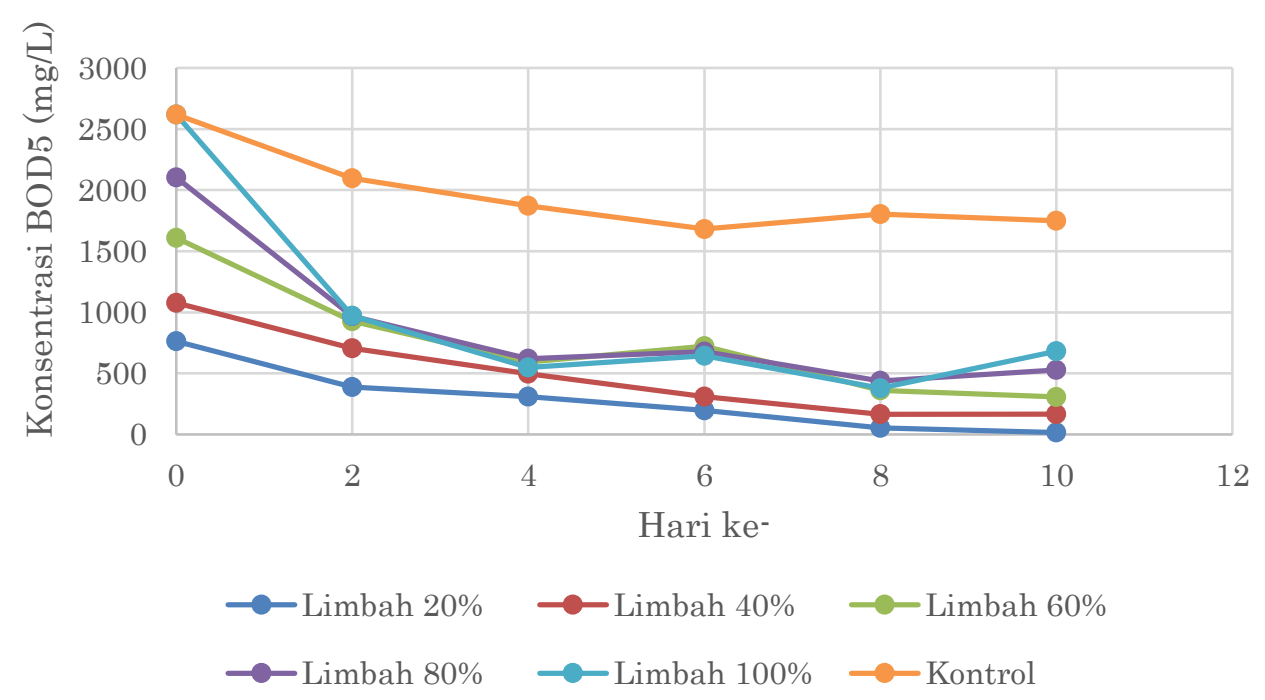

Gambar 1. Tren Penurunan $\mathrm{BOD}_{5}$ dalam reaktor constructed wetlands

\subsection{Tingkat Penurunan COD}

Konsentrasi COD dari air limbah industri tapioka mengalami penurunan selama waktu pengamatan sebagaimana dapat dilihat pada gambar 2. Penurunan COD selaras dengan penurunan BOD, dimana semua variasi konsentrasi air limbah mengalami penurunan hingga hari ke-10. Pada pengamatan hari ke-4, terjadi peningkatan konsentrasi COD untuk variasi air limbah 60, 80 dan 100\% kemudian secara berlahan terjadi penurunan kembali. 


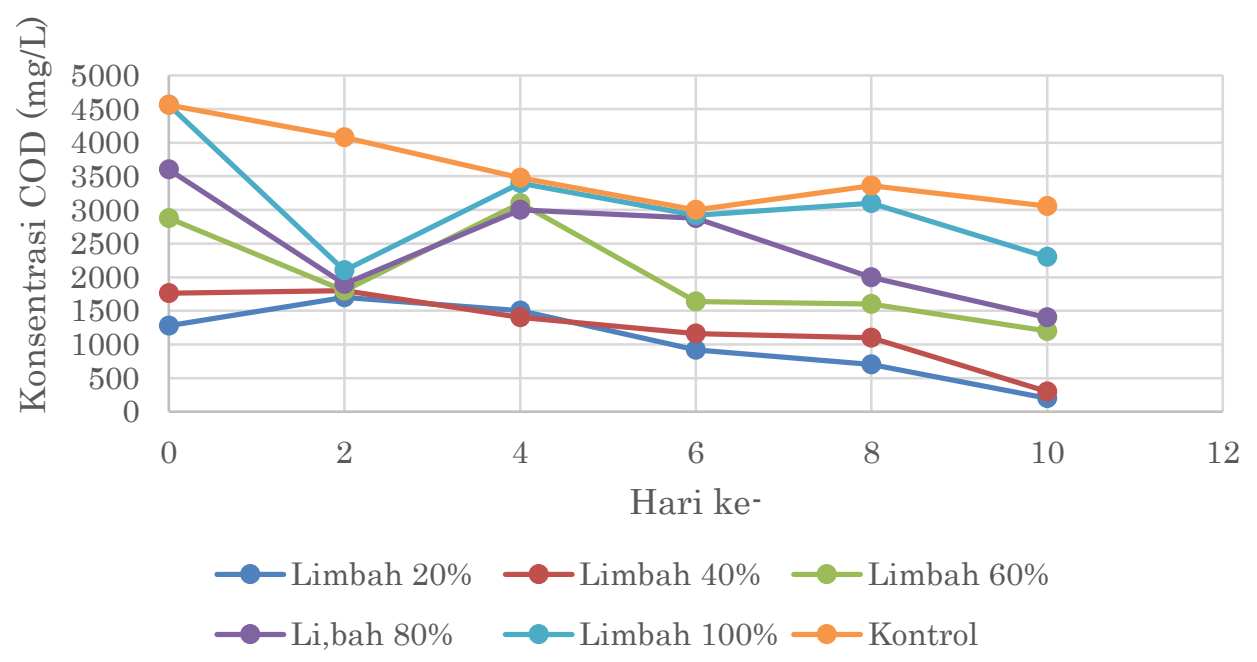

Gambar 2. Tren Penurunan COD dalam reaktor constructed wetlands

Hal ini karena pada konsentrasi yang cukup tinggi memberikan dampak yang kurang baik bagi tumbuhan uji yang ditandai dengan adanya tumbuhan eceng gondok yang mulai mati. Komponen air limbah industri tapioka yang punya toksisitas paling tinggi adalah sianida (Bengtsson and Triet, 1994).

\subsection{Tingkat Penurunan TSS}

Air limbah industri tapioka memiliki kadar TSS dalam jumlah yang cukup besar yang mengalami penurunan sampai dengan hari ke-6 untuk semua konsentrasi air limbah kemudian berlahan mengalami peningkatan. Hal ini dikarenakan adanya tumbuhan eceng gondok yang mati, sehingga air limbah industri tapioka tersebut menjadi semakin keruh. Secara keseluruhan perubahan konsentrasi TSS ditunjukkan pada gambar 3.

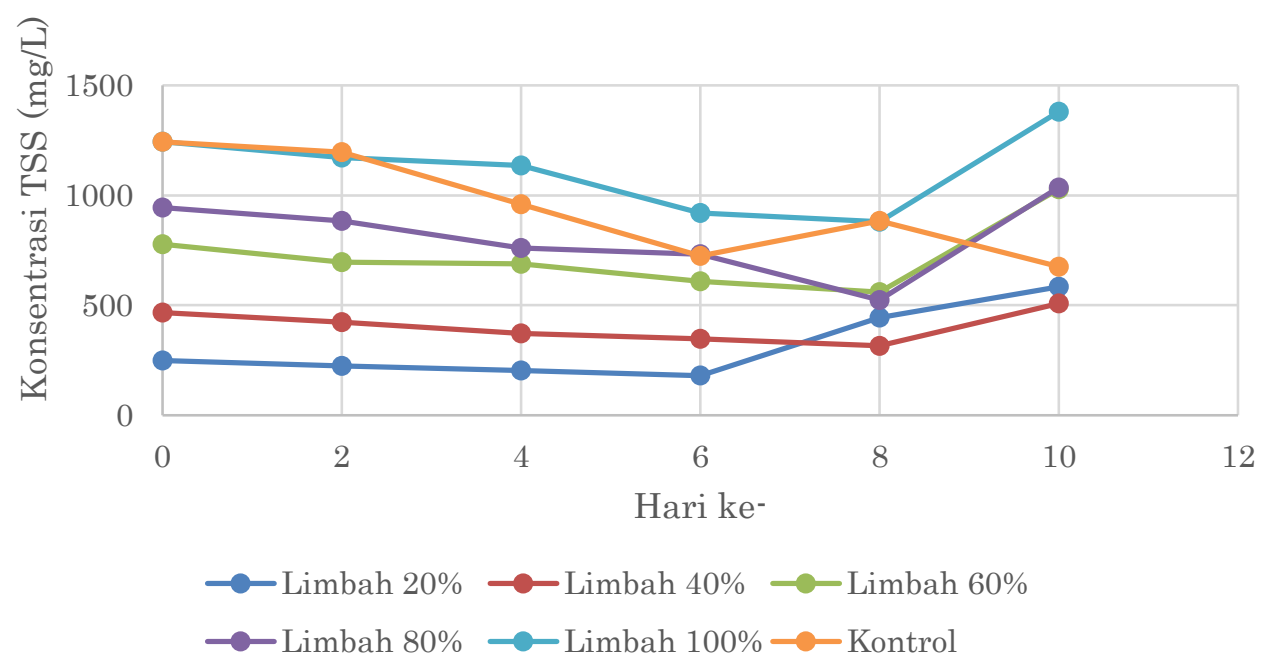

Gambar 3. Tren Penurunan TSS dalam reaktor constructed wetlands 
Data pengamatan dari reaktor kontrol (tanpa tumbuhan) semakin memperjelas bahwa keberadaan tumbuhan yang mati dapat meningkatkan TSS dalm air limbah.

\subsection{Tingkat penurunan Sianida}

Sebagai bahan yang cukup berbahaya, Sianida dalam air limbah industri tapioka yang dijadikan obyek penelitian konsentrasinya cukup besar mencapai 3,29 mg/L, dimana baku mutu yang diijinkan hanya maksimum sebesar $0,5 \mathrm{mg} / \mathrm{L}$. Penurunan sianida tersebut ditunjukkan pada gambar 4.

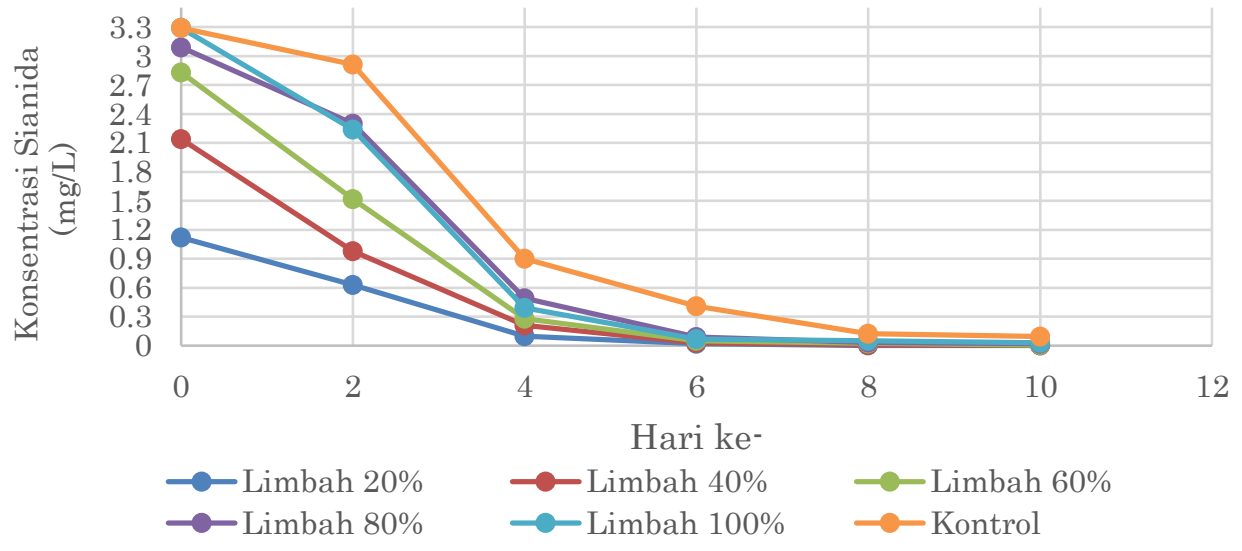

Gambar 4. Tren Penurunan sianida dalam reaktor constructed wetlands

Hasil penelitian ini menunjukkan bahwa sistem constructed wetlands memiliki kemampuan yang sangat baik dalam menurunkan kadar sianida dalam air limbah industri tapioka hingga mencapai di bawah ambang batas maksimum standar yang diijinkan. Tumbuhan yang digunakan mampu menyerap sianida dan mengikatnya dalam akar, batang dan daunnya. Selain itu juga terdapat mikroorganisme yang tumbuh dan bersimbiosis dengan tumbuhan dalam reaktor tersebut (Polprasert, 2004).

\subsection{Toksisitas air limbah industri tapioka terhadap tumbuhan eceng gondok}

Tumbuhan eceng gondok mempunyai kemampuan yang tinggi dalam menurunkan kontaminan dalam air limbah industri tapioka, sehingga secara umum memenuhi baku mutu yang dipersyaratkan. Keberaan kontaminan yang cukup tinggi dalam air limbah industri tapioka memberikan efek negatif pada tumbuhan eceng gondok khususnya setelah beberapa hari (Bengtsson and Triet, 1994). Hasil penelitian menunjukkan bahwa beberapa tumbuhan eceng gondok mati setelah pada hari ke-10, dimana hal ini menjadikan konsentrasi TSS dalam air 
limbah mengalami kenaikan akibat dari tumbuhan eceng gondok yang membusuk. Secara lebih jelas kondisi tumbuhan eceng gondok tersebut dapat dilihat pada Gambar 5.

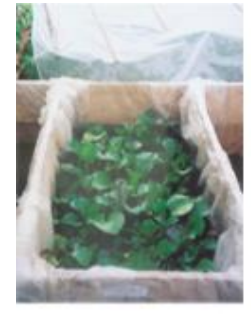

20\%-0

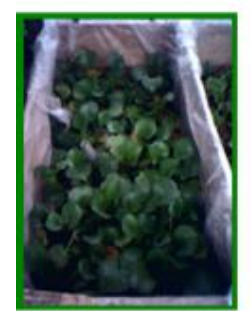

$20 \%-10$

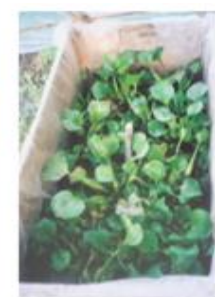

$40 \%-0$

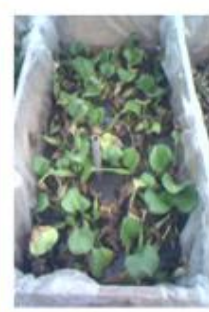

$40 \%-10$

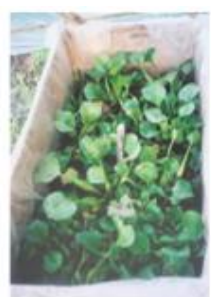

$60 \%-0$

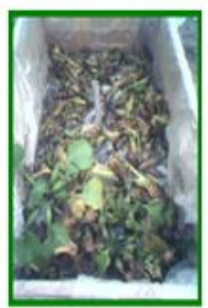

$60 \%-10$
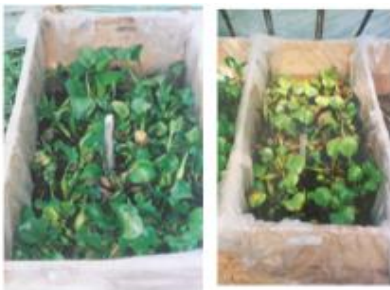

$100 \%-0$

$80 \%-0$

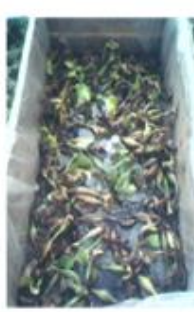

$80 \%-10$

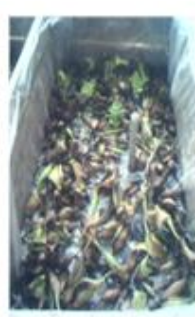

$100 \%-10$

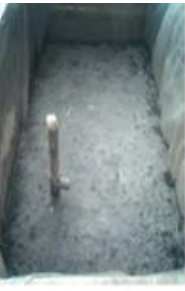

Kontrol

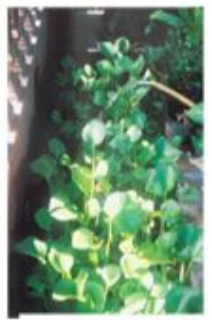

Kontrol

Gambar 5. Kondisi tumbuhan dalam reaktor constructed wetlands

Terlihat sangat jelas bahwa semakin besar konsentrasi air limbah industri tapioka memberikan pengaruh negatif makin besar pada tumbuhan uji. Pada reaktor kontrol (konsentrasi 0\%), tumbuhan eceng gondok dapat hidup dengan subur sampai dengan hari ke-10. Pada konsentrasi air limbah 40\%, tumbuhan eceng gondok masih dapat bertahan sampai dengan hari ke-10. Namun pada konsentrasi selanjutnya kondisi eceng gondok membusuk dan mati. Hasil ini diperlukan untuk desain reaktor pengolahan air limbah industri tapioka sesungguhnya, dimana perlu dilakukan pengenceran terlebih dahulu atau perlu adanya pengolahan pendahuluan (pretreatment) agar diperoleh hasil yang optimum.

\section{KESIMPULAN}

Tumbuhan eceng gondok dalam reaktor constructed wetlands tipe free water surface memiliki kemampuan tinggi dalam menurunkan BOD, COD, TSS dan sianida dalam air limbah industri tapioka mencapai masing-masing 97,9 \%, 84,4 \%, 45,6 \%, dan 99,87\%. Keberadaan mikroorganisme yang bersimbiosis dengan tumbuhan dalam reaktor memegang peranan penting dalam proses penurunan kontaminan dalam air limbah. Dengan kemampuannya yang sangat baik dan keberadaannya sangat banyak serta mudah diperoleh di banyak area, maka sistem ini sangat berpotensi untuk dijadikan salah satu alternatif dalam mengolah air limbah 
industri tapioka atau limbah lainnya, sehingga diharapkan mampu mengurangi permasalahan lingkungan.

\section{DAFTAR PUSTAKA}

Bengtsson, B., and Triet, T. (1994). Tapioca-Starch Wastewater Toxicity Characterized by Microtox and Duckweed Tests. Ambio, 23 (8): 473-477.

Cesaria, R.Y., Wirosoedarmo, R., dan Suharto, B. (2014). Pengaruh penggunaan starter terhadap kualitas fermentasi limbah cair tapioka sebagai alternatif pupuk cair. Jurnal Sumberdaya Alam dan Lingkungan, 1 (2) :8-14.

Fatimah, I., dan Wijaya, K (2005). Sintesis $\mathrm{TiO}_{2}$ /zeolit sebagai fotokatalis pada pengolahan limbah cair industri tapioka secara adsorpsi-fotodegradasi. Teknoin, 10 (4): 257-267.

Irmanto dan Suyata. (2010). Optimasi penurunan nilai bod, cod dan tss limbah cair industri tapioka menggunakan arang aktif dari ampas kopi. Molekul, 5 (1): 22-32.

Mulyani, H., dan Prasadja, M.E. (2014). Study of Chlorination Application in Tapioca Wastewater for Cyanide Removal. Waste Technology, 2 (2): 41-43.

Nurkemalasri, R., Sutisna, M., dan Wardhani, E. (2013). Fitoremediasi Limbah Cair Tapioka dengan menggunakan Tumbuhan Kangkung Air (Ipomoea aquatica). Reka Lingkungan, $2(1): 1-12$.

Polprasert, C. (2004). Constructed Wetlands for Wastewater Treatment: Principles and Practices. Wetlands Ecosystems in Asia, 1: 285-310.

Santoso, B. (2010). Proses pengolahan air buangan industri tapioka. Jurnal Ilmiah Teknologi \& Rekayasa, 15 (3): 213-220.

Siswoyo, E., Kasam, dan Abdullah, L.M.S. (2011). Penurunan Logam Timbal (Pb) pada Limbah Cair TPA Piyungan Yogyakarta dengan Constructed Wetlands Menggunakan Tumbuhan Eceng Gondok (Eichornia Crassipes). Jurnal Sains \& Teknologi Lingkungan, 3 (1): 73-79.

Susilo, F.A.P., Suharto, B., dan Susanawati, L.D. (2015). Pengaruh Variasi Waktu Tinggal Terhadap Kadar BOD dan COD Limbah Tapioka dengan Metode Rotating Biological Contactor. Jurnal Sumberdaya Alam dan Lingkungan, 2 (1): 21-26.

Thepubon, T., Choeisai, P., Mungkarndee, P., Choeisai, K., and Syutsubo, K. (2020). Effect of suspended solids removal methods on methane production from tapioca starch wastewater. Engineering and Applied Science Research, 47 (1): 87-92. 
Wardhana, R.K., H.H.D., Mardiah, A., dan Siswoyo, E. (2019). Sintesis biosemikonduktor menggunakanserat nata de cassava dari limbah cair tapioka. Jurnal Sains \& Teknologi Lingkungan, 11 (2): 143-154.

Zhang, W., Xie, L., Yin, Z., Khanal, S.K., and Zhou, Q. (2016). Biorefinery approach for cassava-based industrial wastes: Current statusand opportunities. Bioresources Technology, 215: 50-62. 